\title{
Characteristics of Dr. Mori's Surgery Pericapsular Capsulo-synovectomy Surgery of the Knee Joint with Special Reference to Differences of Opinionin Relation to Synovectomy Surgery Practised Among ERASS and English-Speaking Countries.
}

\author{
Masuta Mori \\ Prof. emeritus \\ Department of Orthopaedic Surgery, Kansai Medical University, Moriguchi, Osaka 570, Japan \\ (Received for publication July 8, 1992)
}

Key words: surgery of RA, pericapsular capsulo-synovectomy, arthritis surgery, synovectomy, capsulosynovectomy

\section{Abstract}

This paper contains

I. A historical review and general indications for surgery of synovectomy in rheumatoid arthritis

II. General indications of joint surgery for RA with various methods of surgery applied to various joints as stages progress.

III. Masuta Mori's knee joint synovectomy

a) precise description of technique.

b) Postoperative treatment

c) One example for deciding the limitation of Dr. Mori's surgical treatment relating to the unstable knee joint

IV. Discussion

A. Summarizing review of Rheumatoid surgery up to the present including Swett, Ghormley, SmithPetersen, London, Vainio

B. Several surgical experiments made by several surgeons in order to enlarge the surgical indications of the Mori surgery technique

V. Conclusion

The Mori surgery technique is obviously less atraumatic in intervention, though there is a greater amount of surgical removal of morbid rheumatoid tissue from the knee than is the Sweet's technique. The Mori technique should be called "Pericapsular Capsulosynovedctomy," by which the real cause of flexion contracture is found in the anterior compartment morbid synovia and morbidly swollen supra and infra patellar fat pads of the Knee joint.

I. A historical review and general indications for surgery of synovectomy in rheumatoid arthritis The medical history of Rheumatoid Arthritis (RA) can be traced back to the latter half of the previous century (1). However, the evolution of rheumatoid arthritis surgery into modern Rheuma surgery has taken place only in less than the last 40 years. During this period, progress was made in the field of joint synovectomy and arthroplasty, 
and surgeon's efforts were essentially concentrated in these two areas. Synovectomy and arthroplasty have taken a leading position in RA surgery. ${ }^{2-4)}$

Supported by both of these and jointly supported by other kinds of surgical methods, rheumatoid arthritis surgery has reached the status of an independent subspeciality in modern orthopaedic surgery. ${ }^{5)}$ From among these, this paper shall discuss "synovectomy." In literature, synovectomy was first introduced for the knee joint in 1887 by a German surgeon Schüller but in tuberculous knee joints by Volkmann in $1877 .{ }^{6)}$ Some of the sugeons subsequent to him involved in the work of synovectomy of rheumatoid arthritis are as follows: Mignon, ${ }^{8)}$ Goldwaith, Murphy, Swett, ${ }^{9-10)}$ Jones, ${ }^{11)} \quad$ Speed, ${ }^{12)}$ Steindler, ${ }^{13)}$ Heyman, ${ }^{14)}$ Allison, $^{15)}$ Boon-Itt, ${ }^{16)}$ Berstein, ${ }^{17)}$ Painter, ${ }^{18)}$ Inge, ${ }^{19)}$ Ghormley. ${ }^{20)}$ Among these the name of Swett should be noted in particular. After 1940, however, surgical performance of synovectomy of the knee joint was almost entirely discarded due to its very poor results. ${ }^{18-20)}$ During the subsequent $15-20$ years or so, practically almost no synovectomy of the knee joint was performed anywhere in the world except for Pardee. ${ }^{21)}$ In regards to the hip and elbow joints, however, things have been slightly different for the knee joint. In the decade of 1940s' Smith-Petersen developed mould arthroplasty ${ }^{23-24)}$ of the hip, which was used early with considerable success in the surgery of RA. He adovocated his technique of synovectomy for the elbow joint. He introduced a new approach and a new idea to the surgeons of his generation as follows:

1) Surgery has to be applied to the rheumatoid joint in its early stage where the process of destruction has been minimal, and to the joint where active inflammatory processes are still under progress.

2) Arthroplasty and synovectomy are worthwhile procedures in RA.

In spite of such epoch-making ideas and knowledge of Dr. Smith-Petersen as early as 1940, it was not until after 1960 that through the work of myself, London and Vainio $(5,22,27)$ synov- ectomy of the knee joint began to enjoy a revival. The knee joint has consistently been a pace maker in the progress of joint surgery in RA. London, in his paper, reported on the most important basic characteristic related to synovectomy on the human knee joint. His conclusions are as follows: ${ }^{22)}$ Early stage synovectomy of the knee joint with a good joint line and with preserved cartilage will give promissing results, whereas the results of a late stage synovectomy in the joint with damaged cartilage are uncertain. The synovectomy technique used by him, however, in an old classical type of synovectomy untilizing an anteromedial skin incision, which we call Payr's incision. ${ }^{1022)}$ In contrast to London's treatment, Dr. Vainio and his colleague, Dr. Laine started a new system of treatment of RA in Heinola, Finland, around 1952, in which the combined unit principle was first adopted and a rheumatologist and an orthopaedic surgeon began to work jointly together. Dr. Vainio $^{27)}$ is an orthopaedic surgeon favored synovectomy of the knee joint. The review on surgical synovectomy of the knee issued from his clinic reported a large number of surgical cases in 1966 with excellent results never seen in previous literature. This report attracted the attention of surgeons around the world. He is one of the real founders of modern R. A. surgery. At this point, the first initial steps were made to establish a new basis for the foundation of modern RA surgery. ${ }^{27}$ ) As was stated previously, synovectomy of the knee joint, once discarded around 1940, started to revive in popularity, particularly with the surgical effort of Vainio, who favored knee joint synovectomy in his clinic. However, the synovectomy ${ }^{27)}$ he used in his clinic was not the same synovectomy as was used by London ${ }^{22)}$ and Swett, ${ }^{910}$ utilizing the old technique of antero-medial skin incision. Dr. Masuta Mori had started using his own technique of synovectomy as early as 1954 on the knee joint. ${ }^{5)}$ About 10 years thereafter, $1963{ }^{28)}$ he submitted his work with surgical results to the April issue of Arthritis and Rheumatism U.S. A. Right after this paper appeared in the journal, he received a letter from Dr. Vainio of 
Finland concerning his wish to start using Dr. Mori's surgical method. He also reported in his letter that he had already discarded the old type synovectomy technique, including Payr's method, and was looking for a new technique.

Since that time Dr. Mori's technique of synovectomy of the knee joint has been referred to as Mori's Incision in Finland and other Scandinavian countries $^{29)}$ and also continental European countries. This is a short historical review of RA surgery, including the Mori's technique for the knee joint.

\section{General indicators of joint surgery for RA with various methods of surgery applied to various joints as stages progress ${ }^{31}$}

Now let us consider the problem of determining stuitable indicators recommending surgery for RA; they can be dealt with from the following three different standpoints:

1) Indicators from the standpoint of the patients' general condition

2) Indicators from the standpoint of the nature of the RA's course

3) Indicators from the standpoint of the stage of the disease in the patient

Provided the general surgical procedure for RA, "synovectomy in the early stage and arthroplasty for the late stage" are performed on what will be the actual surgical procedure for the individaual joint?

The following explains these three matters separately.

1) Concerning the indicators from the standpoint of the patients' general condition, no surgery is recommended for a patient whose general condition is qreatly impaired, meaning failure in any important visceral organs such as the kidney or liver, because joint surgery such as arthroplasty or synovectomy of a major joint is major surgery. Conversely, a patient before surgery needs to be on a good basic general medical regimen; often being aided with various drug treatments. (Please note that the use of steriod hormones as part of basic general medical regimen is not desirable in Dr. Mori's opinion. ${ }^{42)}$

2) Indicators from the nature of the RA disease's course. Statistical surveys show there are at least three courses the disease RA takes. These are classified in the following types:

1) the benign type, 2) the malignant type, and 3 ) the intermediate type, being between the two. These classifications seem to correspond to the following typings: 1) the mono-cyclic type, 2) the progressive type, and 3 ) the polycyclic type. ${ }^{31)}$

Generally speaking, no surgery is indicated for the patient of type one and type two, wheras surgery is often indicated for type three, that is,

Table. 1 Classification of rheumatoid progression

\begin{tabular}{|c|c|c|c|c|c|}
\hline Stnge & Roentgenologic Singns & Muscle Atrophy & $\begin{array}{l}\text { Extra-Articular } \\
\text { Lesions (Nodules } \\
\text { Tenovaginitis) }\end{array}$ & Joint Deformity & Ankylosis \\
\hline I & $\begin{array}{l}\text { Osteoporosis sometimes } \\
\text { no destructive changes }\end{array}$ & 0 & 0 & 0 & 0 \\
\hline II & $\begin{array}{l}\text { Osteoporosis slight } \\
\text { cartilage or subchondral } \\
\text { bone destruction may } \\
\text { be present }\end{array}$ & Adjacent & May be present & 0 & 0 \\
\hline III & $\begin{array}{l}\text { Osteoporosis cartilage } \\
\text { destruction bone } \\
\text { destruction }\end{array}$ & Extensive & May be present & $\begin{array}{l}\text { Subluxation ulnar } \\
\text { deviation and/or } \\
\text { hyperextension }\end{array}$ & 0 \\
\hline IV & $\begin{array}{l}\text { Same as III } \\
\text { with bony ankylosis }\end{array}$ & Extensive & May be present & Same as III & $\begin{array}{l}\text { Fibrous or bony } \\
\text { ankylosis }\end{array}$ \\
\hline
\end{tabular}

Steinbrocker, O., Traeger, C. H. and Betterman, R. C.:

THERAPEUTIC CRITERIA IN RHEUMATOID ARTHRITIS. J. A. M. A., 140, 8, 659-662, 1939 
the patient of the polycyclic or the intermediate type. As previously mentioned, the patient's general condition has to be examined before surgery.

3) The next consideration before surgery is with regard to the patient's local condition. ${ }^{31)}$ This is referred to as local indication of surgery. The well-known $\mathrm{x}$-ray classification of rheumatoid arthritic joints that is an anatomical stage classification set forth by Steinbrocker ${ }^{25) 26)}$ in order to evaluate structual damage already developed in the affected joint. Such individual joint affection is classified as stages: 1) the "early" stage, 2) the "moderate" stage, 3) the "severe" stage, and 4) "terminal" stage, according to Steinbrocker as shown in Table 1. A joint from stage. 1 to 2 is called an early stage joint, whereas a joint from stage 3 to 4 is called a late stage joint.

A joint in the early stage still has a joint line and cartilage; in this case a synovectomy or, more accurately, an early synovectomy, is indicated. In contrast, in the late stage where the joint is more destroyed, arthroplasty is indicated. Synovectomy in the late stage is called late stage synovectomy or late synovectomy which, however, until now has not been recommended. It can now be said, however, that the results have improved and are excellent compared to before, for late stage synovectomy once the methods herein were introduced ${ }^{31)}$ for the stage III.
In general, the stage of the joint is closely correlated with the class of the patient, ${ }^{25)}$ because a patient is liable to become functionally disabled as his stage progresses. Nevertheless, until now synovectomy is in the early stage and arthroplasty in the late stage has been practiced as a generally accepted principle in RA surgery.

III. Masuta Mori's knee joint synovectomy

In this paper it is intended that the effectiveness of late stage synovectomy, which can be used even in place of arthroplasty in the rheumatoid elbow, wrist, knee or ankle joints, be pointed out. It is the thesis of this paper that the late stage (third stage) synovectomy is widely useful for the knee, elbow, ankle or wrist joint.

Having explained the general surgical practices in $\mathrm{RA}$, that is, the practice of synovectomy for the early stage and arthroplasty in the late stage, let the following question be posed. How is this surgical principle applied in relation to the various individual joints? The answer to this question will be shown in Table 2 following. In this table you can see the type of surgery introduced to individual joints which varies a great deal from one joint to another.

Using Dr. Mori's late stage (third stage) synovectomy of the knee, ankle, elbow and the wrist, very good results have been obtained. Therefore,

Table. 2 Dr. Mori's method of surgery applied to individual joints in relation to the destructive stage according to Steinbrocker

\begin{tabular}{c|c|c|c|c|c}
\hline joint & Hip & Knee & Ankle & Elbow & Wrist \\
\hline 1 & & & & & \\
\hline 2 & A & S & S & S & S \\
\hline 3 & A & S & S & S & S \\
\hline 4 & A & A\&S & A & A\&S & S\&F \\
\hline salvage & F & F & F & F & F
\end{tabular}

S: Synovectomy

A: Arthroplasty

F: Fusion 


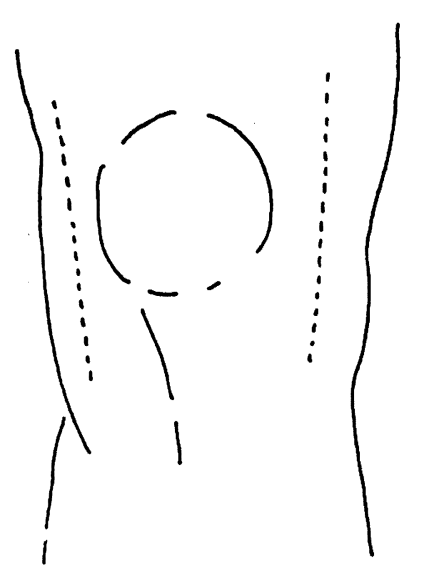

parapatellar skin incisions

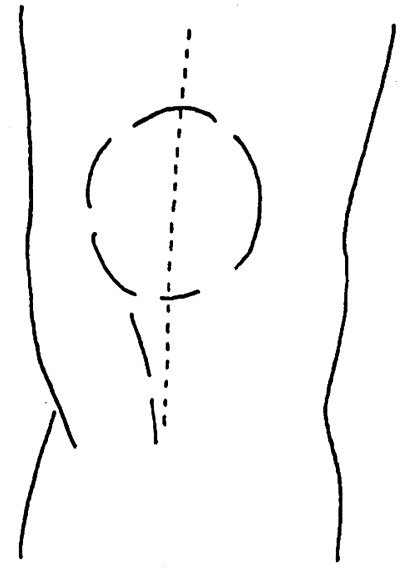

straight longitudinal
skin incision
(new)

Figure. 1 Skin incision

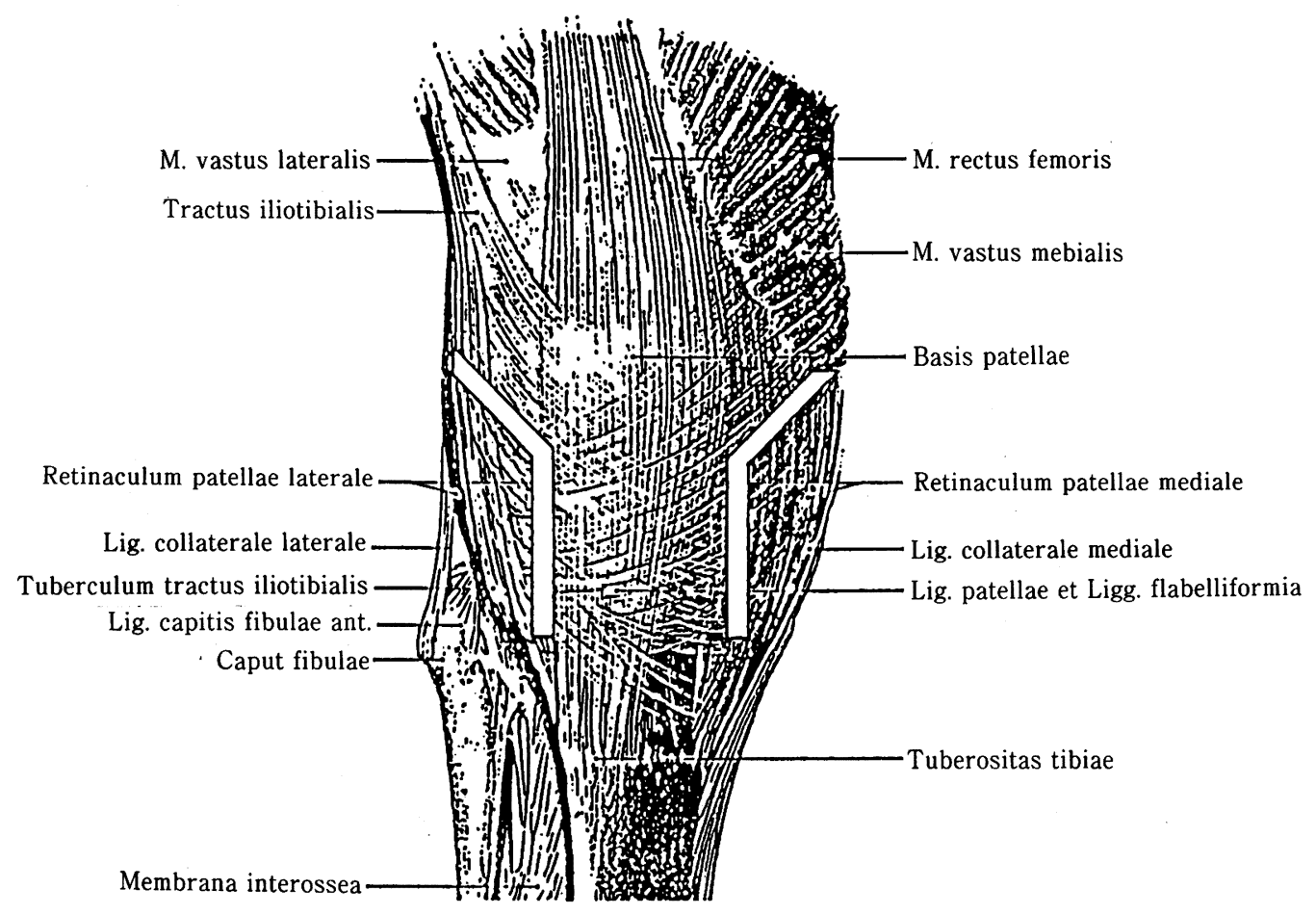

Figure. 2-a Shaped incisions are placed on either side of the patella in tendinous extension of Vastus mediallis and lateralis muscles, seated close to patellar margins (this figure is copied from the Atlas of Lantz's Praktische Anatomie) 


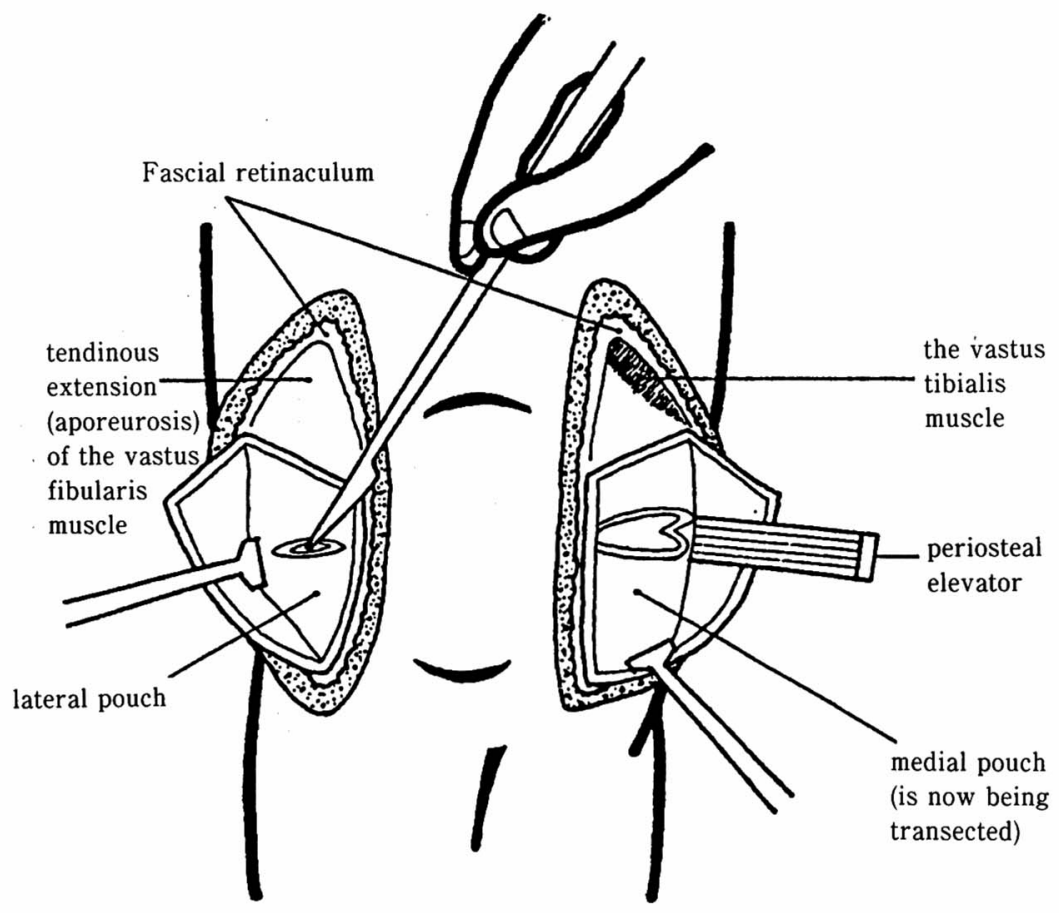

Figure. 2-b After exposure of lateral and medial pouches, a line of arthrotomy is extended horizontally to cut each pouch into upper and lower halves
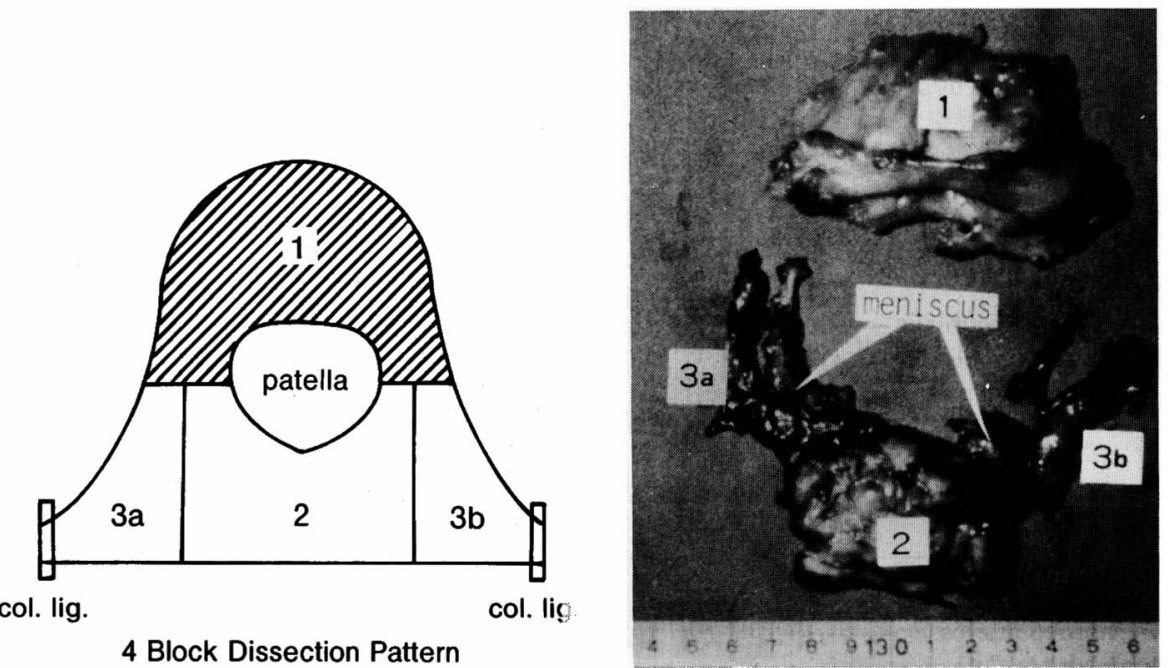

Figure. 2-c 4 block dissection pattern of anterior joint capsule 
as shown in Table 2, fusion operation in the wrist and ankle joints are no longer done in Dr. Mori's clinic except for the case where fusion is used only as a salvage operation.

Concerning to some technical aspects of Dr. Mori's synovectomies in practice, there are four kinds of major joint synovectomy used on the knee, elbow, ankle and wrist in Dr. Mori's clinic. Among them, let the knee joint synovectomy be mentioned first and then proceed to the other joints as space allows. (The wrist joint synovectomy is included in Dr. Mori's Taipei lecture. The present talk on the knee joint synovectomy might be duplicated with the topic of Dr. Mori's talk in Taipei. However, this paper will try to explain it in more detail, and in doing so it is hoped here that the methods will be used and the results compared to the results of other methods, if it is possible.) ${ }^{31)}$

A. What follows is a detailed explanation of individual surgical technique. There is only an explanation of the technique for the knee joint synovectomy in which two main characteristics are involved. The first characteristic is that two skin incision are made on either side of the patella to avoid surgical damage to the quadriceps muscle. ${ }^{31)}$ (Fig. 1)

This surgical approach, first reported in the April 1963 issue of Arthritis and Rheumatism in the U.S. A., now bears the name Moris Incision and is widely used in Germany and Scandinavian countries. $^{29)}$

Now in place of these two incisions a single longitudinal midline incision is being used, as shown in the Fig. 1 for the case where arthroplasty might be considered in the future. Here it can be seen how complete protection is secured for the extension mechanism of the knee joint. (Fig. 2-a)

The second characteristic of Dr. Mori's method of knee joint synovectomy is the entire removal of both synovial and capsular layer tissues from the anterior compartment by using what is called the "four block capsular dissection technique" as shown in the Fig. 2-a, 2-b and 2-c.

The order of doing this four block capsular dissection technique is as follows:
1) Block 1 mainly comprises removal of the suprapatellar pouch along with the surroudning fat tissue;

2) Block 2 mainly comprises removal of the infrapatellar fat pad and its surrounding tissue;

3) and 4) Blocks 3a and 3b removal. Block 3a and $3 \mathrm{~b}$ include removal of both menisci. (Fig. 2-c)

All the granulation tissue such as pannus and granulation filling the intercondylar space has to be debrided thoroughly from the anterior compartment. Furthermore, the posterior compartment has to be debrided. Thorough and meticulous curettage procedure is abso-

PREOPERATIVE: FLEXION CONTRACTURE OF THE KNEE

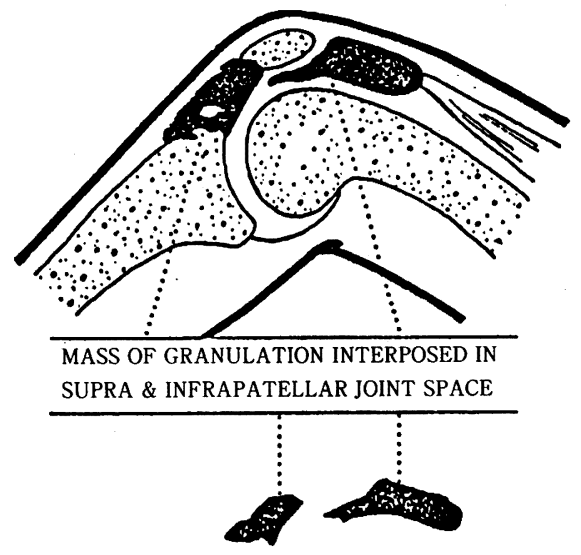

SURGICAL: OPERATIVE REMOVAL OF GLANULATIONS

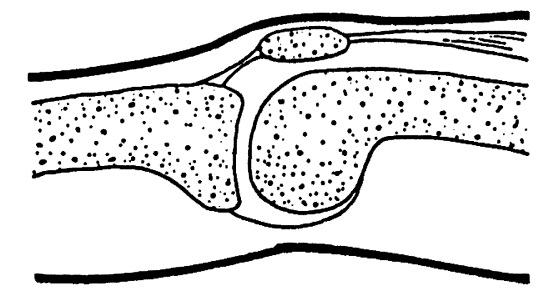

POSTOPERATIVE: FLEXION CONTRACTURE IS CORRECTED

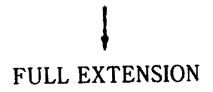

Figure. 3 The cause and way of treatment of flexion contracture of the knee

Supplement to J. Kansai Med. Univ., 44, Dec. 1992 
lutely essential in the posterior compartment débridement $^{3147)}$ (Fig. 2-c)

B. Postoperative treatment ${ }^{31 / 47)}$

Postoperative treatment varies a great deal depending upon the preoperative condition or type of the disease Generally, early commencement of joint motion is recommended except for unstable type knee joint.

Among these synovectomies only Knee is explained.

Table. 3 Different types of late stage knee joint according to the preoperative findings
1. regular
2. contracted
3. unstable
4. angular

The knee joint that we call regular type, in which preoperatively neither contracture nor instability is present, is placed postoperatively in a position of about 90 degrees of flexion.

The flexed and contracted preoperative knee joint is placed postoperatively in a position of maximum extension with skin traction. Early commencement of joint motion is recommended in these two types of knee joints except for unstable knee joints. It will no doubt be found amazing that long-lasting marked flexion constracture can sucessfully be correctable by the Dr. Mori's method. (Fig. 3)

Figure 3 illustrates that there are two big granulation masses made up from the suprapatellar pouch and infrapatellar fat pad which are the main obstructions to knee joint extension. Adhesions take place between the suprapatellar pouch and quadriceps, which has usually been weakened, and also between the patellar ligament and infrapatellar fat pad. In addition, the joint capsule itself may become adherent and shortened. Therefore, smooth extension and flexion movements are impossible unless this adherent and shortened anterior joint capsule is completely removed. The removal of these causative tissue is easily possible, using this operative procedure. ${ }^{28) 31 / 32) 34) 35)}$ (Fig. 3)

C. Synovectomy indication for surgery for unstable knee joint of rheumatoid arthritis

It is commonly accepted that when instability

Table. 4 The surgical series

\begin{tabular}{|c|c|c|c|c|c|c|c|c|}
\hline $\mathrm{Non}$ & Name & Sex & Age $(y)$ & \multicolumn{2}{|c|}{ Range of Motion } & \multicolumn{2}{|c|}{$\begin{array}{c}\text { A-P Laxity } \\
\text { preop. postop. }\end{array}$} & $\begin{array}{l}\text { Follow-up } \\
\text { (mos) })\end{array}$ \\
\hline 1 & K. Y. & $\mathrm{F}$. & 61 & r. $10^{\circ}-90^{\circ}$ & $10^{\circ}-90^{\circ}$ & $13.0 \mathrm{~mm}$ & $5.0 \mathrm{~mm}$ & 44 \\
\hline 2 & T. 0. & M. & 53 & $10^{\circ}-100^{\circ}$ & $0^{\circ}-75^{\circ}$ & 18.2 & 12.2 & 33 \\
\hline 3 & T. Y. & F. & 54 & $10^{\circ}-135^{\circ}$ & $5^{\circ}-130^{\circ}$ & 16.9 & 1.1 & 15 \\
\hline 4 & C. $\mathrm{K}$. & F. & 41 & $30^{\circ}-90^{\circ}$ & $5^{\circ}-85^{\circ}$ & 14.1 & 2.1 & 18 \\
\hline 5 & U. H. & M. & 66 & $10^{\circ}-120^{\circ}$ & $15^{\circ}-65^{\circ}$ & 16.2 & 3.0 & 10 \\
\hline 6 & E. S. & F. & 24 & $0^{\circ}-135^{\circ}$ & $5^{\circ}-100^{\circ}$ & 14.0 & 2.8 & 16 \\
\hline 7 & T. 0. & F. & 52 & $10^{\circ}-140^{\circ}$ & $0^{\circ}-95^{\circ}$ & 21.2 & 6.0 & 7 \\
\hline 8 & T. A. & M. & 59 & $10^{\circ}-150^{\circ}$ & $10^{\circ}-135^{\circ}$ & 17.1 & 6.8 & 14 \\
\hline 9 & & & & $10^{\circ}-150^{\circ}$ & $30^{\circ}-120^{\circ}$ & 16.5 & 11.9 & 9 \\
\hline 10 & M. N. & F. & 55 & $20^{\circ}-140^{\circ}$ & $0^{\circ}-120^{\circ}$ & 12.6 & 11.8 & 23 \\
\hline 11 & & & & $15^{\circ}-140^{\circ}$ & $0^{\circ}-130^{\circ}$ & 14.6 & 5.5 & 20 \\
\hline 12 & M. $\mathrm{O}$. & F. & 55 & $5^{\circ}-125^{\circ}$ & $5^{\circ}-110^{\circ}$ & 7.9 & 4.7 & 16 \\
\hline 13 & Y. S. & F. & 54 & $10^{\circ}-120^{\circ}$ & $15^{\circ}-85^{\circ}$ & 10.8 & 1.8 & 11 \\
\hline 14 & H. A. & F. & 60 & $10^{\circ}-140^{\circ}$ & $0^{\circ}-120^{\circ}$ & 11.2 & 10.7 & 11 \\
\hline 15 & M. Y. & F. & 59 & $10^{\circ}-140^{\circ}$ & $5^{\circ}-110^{\circ}$ & 19.8 & 4.3 & 8 \\
\hline & Aver & & 53.8 & $11.3^{\circ}-127.7^{\circ}$ & $7.0^{\circ}-104.7^{\circ}$ & 14.9 & 6.0 & 17 \\
\hline
\end{tabular}


has markedly developed in the rheumatoid knee, that synovectomy is no longer recommended, but arthroplasty is the treatment of choice. ${ }^{31)}$ The Mori method challenges this concept from its clinical data. Shown in Table 5 are 15 joints of 13 classical cases of rheumatoid arthritis whose diagnosis, age, sex distribution, the side operated upon and duration of disease are shown. Pre-operative, walking is highly impaired by pain, swelling and a clearly noticeable instability, which is measured by translateral slide of the tibia with the knee joint in 90 degrees in flexion. Fig. 4 shows the Xray findings of 3 cases of unstable knee joints operated on in this series which have no gross destruction in X-ray.

After would closure, in the majority of our instability cases plaster of of Paris is applied to the immobilized knee joint for a period of about 2-3 weeks with the knee joint in a position of about 30 degrees of flexion.

The surgical results following this type of synovectomy in the unstable knee are shown in Table 5[1] and 5[2]. The average follow-up period has been 17 months, ranging from 7 months to 4 years. The clinical data before and after surgery is herein noted and compared. Table 5[1] shows a decrease in severe pain and improvement in ability to walk; and Table 5[2] shows a marked improvement in the soft tissue swelling, and an average reduction in Range Of Motion (ROM) from 116 degrees before surgery to 98 degrees after surgery. An extension lag. in an average of 7 degrees, ranging from 0 to 30 degrees is indicated.

Fig. 5 shows the radiological findings before and after surgery, revealing that there was no significant change when Larsen's 6 grade classification criteria was used.

There are at least two kinds of types in the progression of indiviaual joints. One is the high grade contracture type joint which is responding better than the other type, the unstable type. The unstable type of the knee joint is where overstretching or absorption processes are taking places in the bony hard tissue or there is only seeming progress in the soft tfssue and there is poor response to treatment. These results from Dr.

\section{Representative}
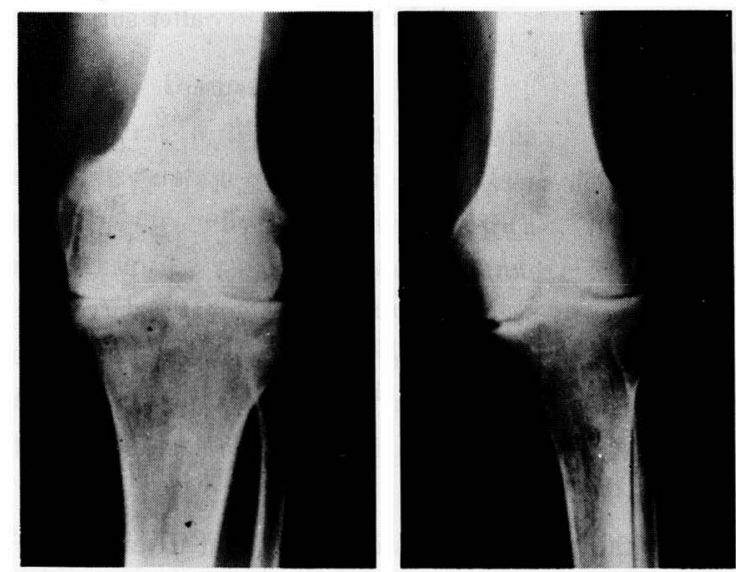

Joint Space Narrowing

Angulatory Deformity (varus or valgus)

Bony Destruction Of Joint

\section{X-ray Films}

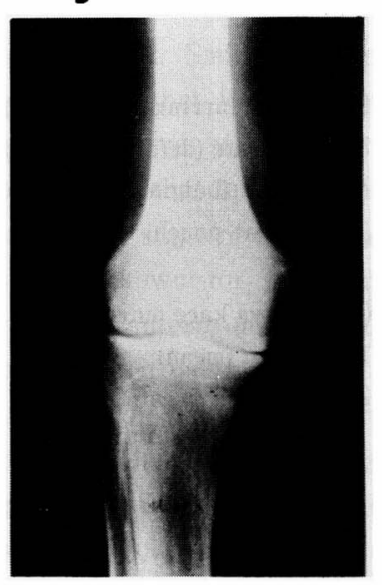

marked in all cases

slight

slight

Figure. 4 A surgical case of an unstable knee 
Table. 5-(1) Eular knee assessment chart

Detailed asscssment symptoms and functional ability

(1) Severity of Pain (this grading should categorisc the severest pain experienced by the patient)

1. None

2. Mild pain, not interfering with activities and/or sleep before surgery after surgery

3. Significant pain, activities reduced and/or sleep

4. Severe pain, with major loss of funetion

(2) Ability to walk

before surgery

after surgery

1. Unlimited

2. $1 \mathrm{~km}$ (but still slightly restricted)

0

0

3. Up to $1 \mathrm{~km}$

4. Up to $500 \mathrm{~m}$

5. $50-100 \mathrm{~m}$ outdoors

6. Indoors only

7. Unable to walk

Table. 5-(2) Eular knee Assessment chart

Detailed asscssment Physical examination

(1) Soft tissuc swelling (synovial hypertrophy and/or offusion)

1. Nil

$\begin{array}{cc}\text { before surgery } & \text { after surgery } \\ 0 & 12 \\ 0 & 2 \\ 8 & 0 \\ 6 & 0\end{array}$

(2) Aetive knee movement

$\begin{array}{cc}\text { before surgery } & \text { after surgery } \\ 120.4^{\circ} & 93.3^{\circ} \\ 12.9^{\circ} & 6.3^{\circ}\end{array}$

2. extension (mean)

$12.9^{\circ}$

0

2

2

3

1

3

1
Mori's soft tissue surgery, compared with the effectiveness of the arthroplasty, showed that that the soft tissue surgery proved not to be recommendable for unstable knee joints, although there is some degree of diminution of preexisting instability. This is regrettable and due to an insufficient amount of post-operative diminution of antero. postero knee joint instability.

However, as the history of the soft tissue surgery is short and iaconclusive, there is hope that in time, this miserable condition may be overcome or will become controllable by using soft tissue surgery only, not by using arthroplasty. 

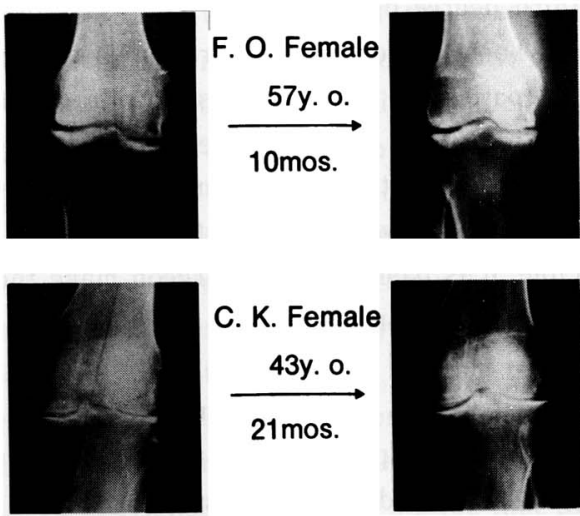

\section{K. Female $43 y .0$ 21 mos.}

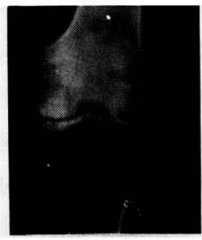

\section{T. A. Male} $60 y .0$. 7 mos.
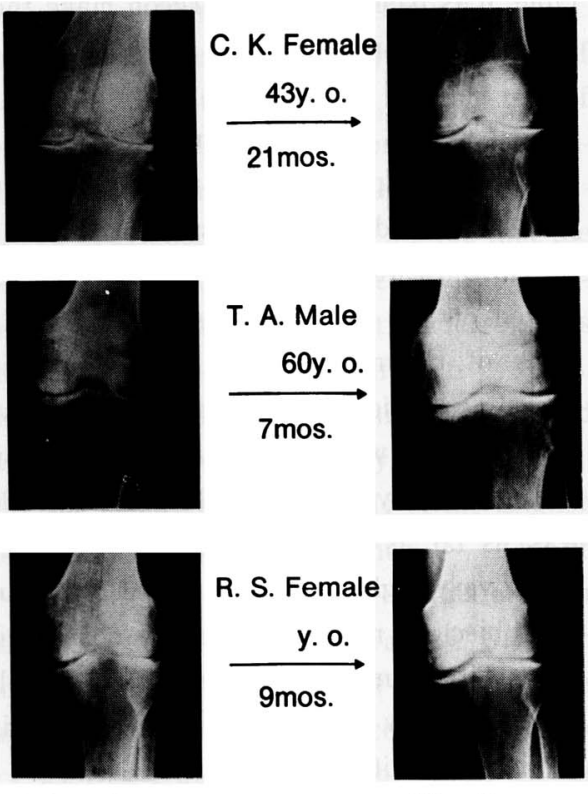

Before Surgery

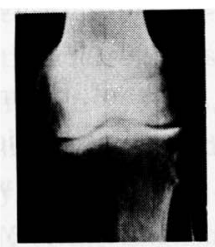

After Surgery
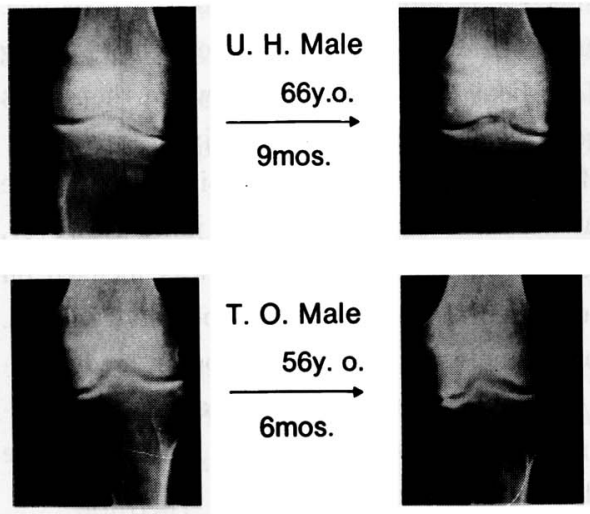

\section{T. O. Male

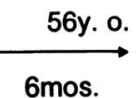
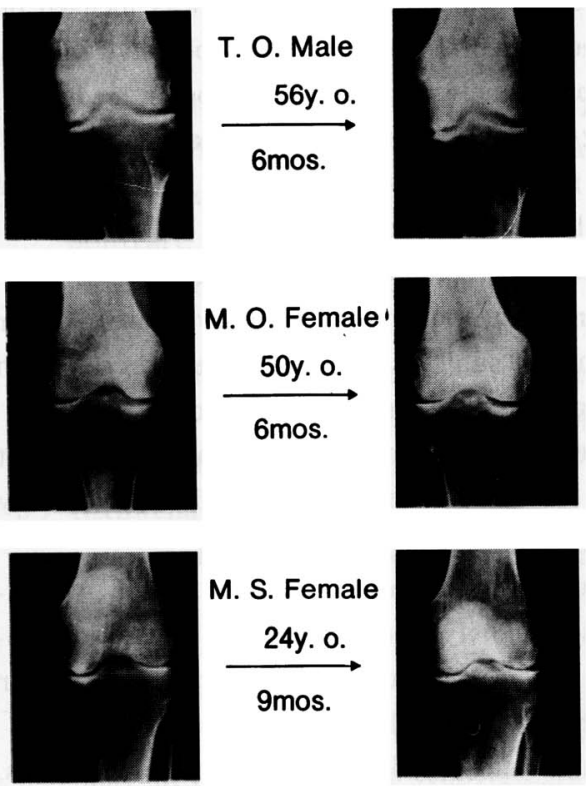

Before Surgery

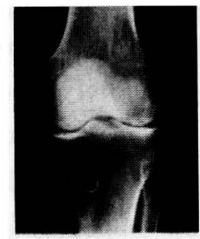

After Surgery

Figure. 5 Radiological findings before and after surgery

\section{Discussion}

In this article, first a historical review was made particularly in relation to Dr. Vainio, the late Prof. emeritus whose friendly communication with Dr. Mori continued until his passing away on January 18, 1990. He trained many Rheumasurgeons under himself at Heinola, Finland and he had assumed the position as honorary member of European Rheumatoid Arthritis Surgical Society (ERASS).

As for the historical review there are two faces concerned with surgical synovectomy in general. One has a century-long history: over 100 years have passed since the work reported by Volkmann, and more than 60 years have passed since the era of P P Swett ${ }^{9 / 10)}$ and followers when the rheumatoid inflammation was regarded as kind of low grade infectional focus. Smith Petersen ${ }^{23) 24)}$ was the first who decided that RA surgery should be done even at the active stage, contrary to the hitherto accepted idea that surgery could be done only during quiescent stage of inflammation. Swett, $1923,{ }^{9) 10)}$ is well known for his adovocation of synovectomy using antero-medial skin incision around the patella as a useful surgical means, but the new idea of an indication for surgery is coming from the cup arthroplasty of the hip joint, where the joint capsule tissue itself is totally removed from the hip joint. That was in the year of 1948 in literature.

Since the above, 45 years have passed. On the other hand, Dr. Vainio maintained another face. Vainio began enthusiastic surgical work on the knee joint form the decade of the 1960s. He was a founder of modern Rheuma-surgery. If so, the his- 
torical review is only less than 40 years of age. Some surgeons can look back upon their young days of medical life around 1960 when there was no surgery at all for RA, particulariy in Japan.

Dr. Mori started from the knee joint, although he began at the same time with other joint. However, it seemed for him that everything was focused on the knee, supported by favorable operative results. Therefore, conclusions were near being made concerning the knee joint. Although the surgical techniques shared by several surgeons can widen the surgical indications considerably.

Among them the purely technical can be separated from the purely postoperative care. As for the technical subjects the precious efforts to widen the surgical indications were as follows:

1) The devices done by Vainio in which, except for the children menisectomy is done for every adult knee joint case. ${ }^{37) 38 \text { ) }}$

2) The devices done by Tillmann which ${ }^{39-41)} \mathrm{ex}$ ecute secondarily the addition of posterior approach to the posterior compartment and in order to do the more complete joint capsule removal. ${ }^{39-}$ ${ }^{41)}$ He never fails to do menisectomy on both sides. This action of doing menisectomy becomes the greatest reason for his present opinion against arthroscopic surgery.

3) The current surgical devices (thorough curettage work) widely enough to cover the wide area neighboring to articular femoral cartilage have been used by Dr. Mori recently.

As for the pure postoperative cares:

1) At the time of Dr. Mori's 1961 publication, manipulation procedure by use of intra-venous anesthesia was performed on the operated knee joint 10 day following surgery. Although this method that was routine until 20 years ago has been given up, Dr. Mori would like to try it again if it were allowed. ${ }^{5 / 34)}$

2) Subsequent to the presentation in this article, it was clarified that the unstable knee is resistant to this type of surgical method. In spite of this, Dr. Mori personally recommended that patients not use any type of medicating steroid hormone because the steroid hormone belongs to the third degree drug group. ${ }^{42)}$ The usage of the steroid hormone for a long duration of time will lead the patient to have unpleasant side effects which are inevitable or impossible to avoid. Also, at the same time, rest for the patient's physical as well as mental well-being is absolutely necessary. In principle, it is basic that the surgeon make the patient take care of himself.

\section{Conclusion}

Here this type of soft tissue surgery on the knee joint is concluded as follows:

In 1985 Brattström, Mori, Gschwend et $\mathrm{al}^{43)}$ reported on the long term results summarizing the work of rheuma surgeons from seven countries and nine clinics. A total of 508 knee surgeries were graded with the results being subjectively and objectively good with 329 knees (65\%); there was, as far as it could be concluded from the reports, very high conformity between the subjective and objective results. The mean observation time was 12.6 years and the reported complications were very few (only one case of serious infection was reported; it ended in fusion).

The mean grade, according to Larsen, was 1.7 preoperative and 2.7 postoperative. It was undoubtedly difficult to judge the reports from retrospective studies of nine different clinics with a lack of conformity between the subjective and objective results on the one hand and the radiological changes in the order, on the other. Good subjective and objective results were very often associated with roentgenological deterioration.

"We do think, however, that this study has shown that synovectomy of the knee in early cases with rheumatoid arthritis is a good, time-gaining operation. This is specially important because our knee prostheses are, without discussion, not yet as successful as those of the hip; and if by performing a synovectomy we can postpone a knee arthroplasty by some years, we will have better prosthese , better techniques in cementing (or not cementing) them, and know more about how to avoid and treat the complication. If, with a synovectomy we can give freedom from pain and swelling for more than 
ten years in about two-thirds of the cases by means of a simple harmless operation and give the patients some comfortable years, it will be well worth it. By so doing, one leaves no burnt ship behind like the Vikings did, because one can always come back and make an arthroplasty, an osteotomy, a fusion or even a resynovectomy."

The above sentences, inspired by the reports of nine clinics, are quotation from the original text of Brattström himself. It has been strongly that Brattström obviously intended to protest the conclusions gained previously to him ${ }^{44) 45)}$ stating that the early stage synovectomy was not advisable because of the pessimistic study of the end-results of knee surgery on an average after five years. Thus the opinion of Brattström which represented ERASS is still at present contrary to that represented by the majority of the people of the English speaking countries and of the French. ${ }^{40) 43)}$ This in fact is a tragedy. In the end, after thinking over and over about the cause of this tragedy, Dr. Mori came to the conclusion that Dr. Vainio's and his surgical techniques could be placed in the same category as Drs. Swett and London, even though there were surely technical differences between his methods and theirs. (Swett and London)

This is the main reason for emphasizing the differences between the two in this paper. Such a discrepancy of opinion has to be eliminated with a comparison being made between the two methods. This is the opportunity to clarify the differences between them.

The most important conclusion in Mori's knee joint synovectomy is as follows. Two benefits do exist in the surgical technique which should fall under the name pericapsular capsulo-synovectomy.

1) Surgical intervention is the more atraumatic in nature and the removal of rheumatoid tissue from the knee joint promises to bring about much amount of intra articular morbid tissue than in Swett's technique ${ }^{31)}$ and 2) real cause of flexion contracture is not in the posterior compartment but in the anterior part, such ass intraarticlar rheumatoid tissue and supra and infra patellar fat pad concerned with the anterior compartment. ${ }^{31)}$
Dr. Mori's personal opinion is in opposition to Drs. Windsor and Insohl, who consider the main cause flexion contracture of the knee joint to be in the posterior compartment as well as in the posterior structures. $^{46)}$

\section{References}

1) Volkmann R: Operation on the knee joint. In Surgical Treatment of Rheumatoid Arthritis: (Gschwend N Ed), 203. Georg Thieme Varlag, Stuttgart, 1980.

2) Mitchell N, Shepard N: The effects of synovectomy on synovium and cartilage in rheumatoid arthritis. In Surgery of Rheumatoid Arthritis: (Gruess RL, Mitchell N Eds), Lippincott, Philadelphia, 1971. 5-14.

3 ) Gschwend N: Objective and Nature of the Operations. In Surgical Treatment of Rheumatoid Arthritis: (Gschwend N Ed). Georg Thieme Verlag, Stuttgart, 1980. 18-24.

4) Marmor L: Surgical Treatment. Arthritis Surgery: Lea \& Febiger, Philadelphia, 1976. 41.

5 ) Mori M: Reevaluation of synovectomy in chronic arthritis of the knee. Nippon Seikeigeka Gakkai Zasshi 28: 368-370. 1954. (in Jappanese)

6 ) Geens S: Synovectomy and débridement of the knee is R. A. part 1 historical review. J Bone Joint Surg 51-A: 617-625. 1969.

7 ) Geens S, Clayton MC, Leidholt JD, et al: Synovectomy and débridement of the knee in R. A. part 2 clinical and roentgenographic study of thirty-one cases J Bone Joint Surg 51-A: 626-642. 1969.

$8)$ Mignon MA: Synovectomie de genou. Bull ett Mem Soc Chir Paris 26: 1113-1115. 1900.

9) Swett PP: Synovectomy in chronic infectious arthritis. J Bone Joint Surg 5: 119-121, 1923.

10) Swett PP: A review synovectomy. J Bone Joint Surg 20: 68-76. 1938.

11) Jones E: Synovectomy in the knee joint in chronic arthritis. JAMA 81: 1579-1585. 1923.

Supplement to J. Kansai Med. Univ., 44, Dec. 1992 
12) Speed JS: Synovectomy of the knee joint. JAMA 83: 1914-1920 1924.

13) Steindler A: Synovectomy and fat pad removal in the knee. JAMA 84: 16-20. 1929.

14) Heyman CH: Synovectomy of the knee joint. Surg Gynecol Obstet 46: 127-132. 1928.

15) Allison N, Coons GK: Synovectomy in chronic arthritis. Arch Surg 18: 8244-840. 1929.

16) Boon-Itt SB: A study of the endresult of synovectomy of the knee. J Bone Joint Surg 12: 853-858. 1930.

17) Bernstein MA: Synovectomy of the knee joint in chronic arthritis. Ann Surg 98: 10961108. 1933.

18) Painter CF: The role of synovectomy in chronic infectious arthritis. J Bone Joint Surg 14: 795-800. 1932.

19) Inge GAL: Chronic synovitis of the knee joint treated by synovectomy. JAMA 111: 24512455. 1938.

20) Ghormley PK, Cameron DM: Endresults of synovectomy of the knee joint. Am J Surg 53: 455-459. 1941.

21) Pardee ML: Synovectomy of the knee joint. J Bone Joint Surg 30A: 908-914. 1948.

22) London PS: Synovectomy of the knee in rheumatoid arthritis. J Bone Joint Surg 37-B: 392-399. 1955.

23) Smith-Petersen MN: Useful surgical procedures for R. A. involving upper extremity. Arch Surg 46: 764-770. 1943.

24) Smith-Petersen MN: Evaluation of mould arthroplasty of the hip. J Bone Joint Surg 30B: 57-75. 1948.

25) Steinbrocker 0, Trager CG, Batterman RC: Therapeutic Criteria in Rheumatoid Arthritis. JAMA 140: 659-662. 1949.

26) Larsen K, Dale K, Eck M: Radiographic evaluation of rheumatoid arthritis and related condition by standard reference films. Acta Radiol Diagn 18: 481-491. 1977.

27) Vainio K: Operations on the knee joint. In Surgical Treatment of Rheumatoid Arthritis: (Gschwend N Ed), Georg Thieme Varlag, Stuttgart, 1980. 208-209.
28) Mori M, Ogawa R: Anterior capsulectomy in the treatment of the Rheumatoid Arthritis of the knee joint. Arthritis Rheum 6: 130-137. 1963.

29) Pahle JA: Synovectomy genus a.m. Mori. In the Book in Honor Mori's Retirement: (Matsushima M. Ed), Fujiseihan, Osaka, 1984. 11.

30) Sakamoto N: Studies on the Meniscus Lesion in the Knee Joint with Rheumatoid Arthritis. Nippon Seikeigeka Gakkai Zasshi 53: 27-41. 1979.

31) Mori M: A review of knee joint synovectomy in $\mathrm{R}$. A. with theoretical and technical consideration. Ann Chir Gynecol 74: 40-47. 1984.

32) Mori M: Synovectomy as a kind of surgery. Nippon Seikeigeka Gakkai Zasshi 57: 9-16. 1983. (in Japanese)

33) Nakamura K: Endresults study of Surgical Synovectomy on the Elbow, knee and Ankle Joint. J. Kansai Med. Univ. 36: 1984. 393-394.

34) Mori M: Anterior total knee joint capsulectomy in the treatment of Rheumatoid Arthritis. Nippon Seikeigeka Gakkai Zasshi 34: 11-23. 1961.

35) Mori M: Surgery of the rheumatoid arthritis of the knee joint. Rheumatism April Issue: 3542. 1964.

36) Gschwend N: Operations on the Spine. In Surgical Treatment of Rheumatoid Arthritis: (Gschwend N Ed), 267-271. Georg Thieme Verlag, Stuttgart, 1980.

37) Eyring EJ: The therpeutic potential of synovectomy in jevenile rheumatoid arthritis. Arthritis Rheum 11: 688-692. 1968.

38) Vainio K, Raunio P: Synovectomy of the knee joint in juvenile R. A. using Mori's technique. In the Book in Honor of Mori's Rreatment: (Matsushima M. Ed), Fujiseihan, Osaka, 1984. 9-10.

39) Tillmann K: Value of synovectomy. In Revisional Surgery of Rheumatoid arthritis: (Schattenkirchner M, Hagena FW Eds), 1990. $1-13$.

40) Tillmann K: Recent advances in the surgical treatment of rheumatoid arthritis. Surgical 
Treatment of Rheumatoid arthritis 258: 6772. 1990.

41) Dummer U, Tillmann K: Comparative evaluation of partial and subtotal synovectomies of the knee joint of R. A. Reconstr Surg Traumat. 18: 8-15. 1981.

42) Dick WC: Grug treatment of R. A. Textbook of Rheumatic Diseases: (Scott JT Ed), 414-416. Churchil Livingstone, Edinburgh, 1978.

43) Brattström H, Mori M, Gschwend N, et al: Long results of knee synovectomy in early case of R. A. Clin Rheumatol 4: 19-22. 1985.

44) Arthritis Foundation Committee of Synovectomy: Multi-center evaluation of synov- ectomy in the treatment of R. A. Arthritis Rheum 20: 765-771. 1977.

45) Arthritis and Rheumatism Council and British Orthopaedic Association: Controlled trial of synovectomy of knee and metacarpophalangeal joints of R. A. Ann Rheum Dis 35: 435-442. 1976.

46) Windsor RE, Insall JN: Correction of arthritic deformities of the knee. In Arthritis and Allied Conditions: 11th ed, (McCarty DJ Ed), Lea \& Febiger, Philadelphia, 1989. 876-888.

47) Hamada A: Follow up results of Mori's Synovectomy of the knee joint in R. A. J Kansai Med Univ 33: 566-586. 1981. 